\title{
COLISÃO DE DIREITOS FUNDAMENTAIS NO ENCONTRO FORTUITO DE CONHECIMENTOS TRADICIONAIS EM PESQUISA CIENTÍFICA NO BRASIL
}

\author{
COLLISION OF FUNDAMENTAL RIGHTS IN THE FORTUITOUS MEETING OF \\ TRADITIONAL KNOWLEDGE IN SCIENTIFIC RESEARCH IN BRAZIL
}

\author{
Marcelo Nogueira \\ Mestre e Doutorando em Propriedade Intelectual e Inovação pelo INPI e \\ MBA/FGV em Direito Tributário (2014). \\ E-mail: mnogueira.adv@gmail.com
}

\begin{abstract}
Alexandre Guimarães Vasconcellos
Graduado em Licenciatura Plena em Ciências Biológicas pela Universidade Federal do Rio de Janeiro (1995), MBA em Gestão de Políticas Públicas (Inovação e Propriedade Intelectual) pelo Instituto de Economia da UFRJ (2006), Mestrado em Ciências Biológicas (Biofísica) pela Universidade Federal do Rio de Janeiro (1998), Doutorado em Biotecnologia Vegetal pela Universidade Federal do Rio de Janeiro (2003) e Pós-doutorado Sênior sobre Gestão da Inovação em Doenças Negligenciadas no Centro de Desenvolvimento de Tecnologia em Saúde da FIOCRUZ (2011) e na Global Challenges Division da World Intellectual Property Organization, Genebra-Suíça (2016). É Pesquisador em Propriedade Industrial do INPI e atua na Divisão de Pós-Graduação e Pesquisa (DIPGP), sendo Professor Permanente da Academia de Propriedade Intelectual e Inovação do INPI desde sua criação em 2006.

E-mail: alexguim@inpi.gov.br
\end{abstract}

\section{Celso Luiz Salgueiro Lage}

Graduado em Física pela Universidade Federal do Rio de Janeiro (1984), mestrado em Ciências Biológicas (Biofísica) pela Universidade Federal do Rio de Janeiro (1989) e doutorado em Ciências Biológicas (Biofísica) pela Universidade Federal do Rio de Janeiro (1995). Pós-doutorado no Departamento de Política Científica e Tecnológica do IG da UNICAMP. Atualmente é Especialista Senior em Propriedade Industrial em Biotecnologia do INPI.

E-mail: clage@inpi.gov.br

Recebido em: 15/09/2020

Aprovado em: 10/03/2021

RESUMO: O objetivo deste artigo é avaliar a segurança jurídica da pesquisa científica sob a ótica do sistema brasileiro de proteção do patrimônio genético e dos conhecimentos tradicionais associados. A situação hipotética proposta é o encontro fortuito de um conhecimento tradicional associado (CTA) de origem identificável, em fonte secundária, no contexto de uma pesquisa científica, já em andamento, que tem por objeto patrimônio genético brasileiro. Pela legislação, não se tratando de levantamento bibliográfico e compilação de informações de bibliografia, a pesquisa não pode prosseguir sem a obtenção do consentimento prévio informado. Tendo em vista que o legislador não enfrentou a questão das camadas de disseminação do conhecimento tradicional associado, configura-se, assim, uma colisão entre direitos fundamentais cujo tratamento precisa lidar com a relação entre disponibilidade do conhecimento e domínio público. A exigência de 
consentimento prévio de acesso ao CTA parece incompatível com a situação onde o CTA já foi acessado através de pesquisa anterior e está disseminado. Nesta hipótese, a justificativa para a negativa de acesso deve ter peso suficiente para se sobrepor aos potenciais benefícios da pesquisa, tendo em vista ainda o peso da contribuição do CTA encontrado fortuitamente face ao conhecimento já estabelecido em relação ao objeto da pesquisa.

Palavras-chave: Conhecimento tradicional. Patrimônio genético. Pesquisa científica. Direitos fundamentais. Propriedade intelectual.

ABSTRACT: The objective of this article is to evaluate the legal security of scientific research from the perspective of the Brazilian system of protection of genetic heritage and associated traditional knowledge. The proposed hypothetical situation is the fortuitous encounter of an associated traditional knowledge (ATK) of identifiable origin, in a secondary source, in the context of a scientific research, already in progress, which has as its object Brazilian genetic heritage. According to the legislation, since it is not a matter of bibliographic survey and compilation of bibliographic information, the research cannot proceed without obtaining prior informed consent. Given that the legislator did not address the issue of the layers of dissemination of associated traditional knowledge, it is thus a collision between fundamental rights whose treatment needs to deal with the relationship between availability of knowledge and public domain. The requirement for prior consent to access the ATK seems incompatible with the situation where the ATK has already been accessed through prior research and is disseminated. In this hypothesis, the justification for denial of access should carry sufficient weight to outweigh the potential benefits of the research, given also the weight of the ATK's contribution found fortuitously in relation to the knowledge already established in relation to the object of the research.

Keywords: Traditional knowledge. Genetic heritage. Scientific research. Fundamental rights. Intellectual property.

SUMÁRIO: Introdução. Metodologia. Resultados e Discussão. Conclusão. Referências.

\section{INTRODUÇÃO}

Quando se fala em biodiversidade brasileira, algumas ideias imediatamente vêm à mente. Uma delas é a grandiosidade da floresta amazônica, dos diversos biomas e do litoral como grandes repositórios da maior biodiversidade do planeta. O benefício de toda esta riqueza econômica, cultural, ambiental e científica, é acompanhado de algumas responsabilidades. A preservação e a gestão deste complexo conjunto tão diversificado não é uma tarefa trivial.

Outra ideia que caminha ao lado da biodiversidade é a biopirataria. Em 1876, Sir Henry Alexander Wilckham levou 70.000 sementes contrabandeadas da Hevea brasilienses de Santarém, no Pará, e as encaminhou para o Royal Botanic Gardens, em Londres, de onde mudas foram encaminhadas para a Malásia. ${ }^{1}$ Em poucos anos, foi possível produzir borracha em larga escala, $o$ que agravou a crise no extrativismo da borracha na Amazônia que terminou desativando milhares de seringais no Brasil (DEAN, 1987).

Também vem à mente o acordo Novartis/Bioamazônia. Em 2000, um acordo de cooperação técnica firmado pela organização social denominada Associação Brasileira para o Uso Sustentável da Biodiversidade da Amazônia (Bioamazônia), braço operacional do Programa Brasileiro de Ecologia Molecular para o Uso Sustentável da Biodiversidade da Amazônia do

\footnotetext{
${ }^{1}$ De acordo com a classificação de Robinson (2010), seria uma modalidade de biopirataria não-patentária por dizer respeito ao controle de recursos biológicos.
}

Revista de Direito Brasileira | Florianópolis, SC | v. 28 | n. 11 | p.117-130 | Jan./Abr. 2021 
Ministério da Ciência e da Tecnologia, com a Novartis, um grupo farmacêutico suíço que atua mundialmente, gerou protestos (JOLY, 2000).

O Acordo de Cooperação firmado pela Bioamazônia com a Novartis previa que a primeira concederia à segunda o direito de acesso e uso exclusivos de material genético vegetal de organismos vivos (germoplasma) pertencente ao vasto território amazônico. A Novartis poderia coletar, identificar, classificar e caracterizar o perfil das cepas e os componentes químicos dos extratos (microrganismos), podendo, ainda, enviar tais materiais para a matriz, situada na Suíça, bem como amostras do solo da Amazônia para continuidade das pesquisas.

A multinacional suíça teria, ainda, licença perpétua e exclusiva, com direito de conceder sublicenças, para produzir, usar e vender produtos contendo o composto original ou derivados, além de quaisquer direitos de patentes ou know-how. A Bioamazônia produziria até dez mil cepas microbianas (fungos e bactérias) e receberia 1\% de royalties sobre o composto novo, durante dez anos. Em contrapartida, a Novartis teria assegurada a propriedade sobre todos os direitos em quaisquer invenções relativas a compostos derivados de microrganismos retirados da Amazônia (PEDRO, 2018).

A comunidade científica se dividiu entre aqueles que apoiavam a iniciativa, por transformar nossa biodiversidade em dólares, outros que entendiam que o valor de US\$3 milhões em 3 anos mais $1 \%$ dos royalties era excessivamente baixo e o único benefício seria a regulamentação do acesso aos recursos genéticos. E ainda havia uma terceira opinião, alinhada com organizações não-governamentais, parte do Conselho Técnico-Científico da própria Bioamazônia e o Ministério do Meio Ambiente que se posicionavam contra o acordo (JOLY, 2000).

Esse acordo foi objeto de denúncia ao Ministério Público Federal brasileiro. Por não prever qualquer forma justa de repartição de benefícios e diante de manifestações diversas da sociedade civil, este acordo foi suspenso e, posteriormente alterado (BRASIL K., 2000; MOREIRA, 2005). Por isso, é considerado o estopim das Medidas Provisórias $\mathrm{n}^{\circ}$ 2.052/00 e $\mathrm{n}^{\mathrm{o}}$ 2.186/01 que inauguraram a legislação brasileira sobre o tema, antecedendo a atual Lei Federal $n^{\circ} 13.123 / 15$ (PEDRO, 2018).

Esta sucessão de fatos ajuda a entender a posição de vanguarda do Brasil na regulamentação da matéria. Dentre 110 países analisados, sessenta e nove não possuem uma legislação de acesso ao patrimônio genético e conhecimentos tradicionais associados e apenas vinte e um possuem um procedimento específico para o acesso aos conhecimentos tradicionais (CNI, 2017). Também é possível entender o rigor e a nítida preocupação com a indústria farmacêutica nesta legislação.

Tendo como um de seus objetivos a rastreabilidade do uso da biodiversidade e dos saberes dos povos ancestrais, a legislação brasileira em questão exige dos usuários do acesso ao patrimônio genético e aos conhecimentos tradicionais associados o cadastro de algumas atividades em um sistema de base de dados. Estas atividades estão divididas em três grandes grupos: pesquisa, desenvolvimento de produto e exploração comercial.

Em razão disso, a pesquisa científica, definida na lei como "atividade, experimental ou teórica, realizada sobre o patrimônio genético ou conhecimento tradicional associado, com o objetivo de produzir novos conhecimentos, por meio de um processo sistemático de construção do conhecimento que gera e testa hipóteses e teorias, descreve e interpreta os fundamentos de fenômenos e fatos observáveis" (BRASIL, 2015), foi submetida às regras desta legislação.

Segundo estas regras, não se tratando de levantamento bibliográfico e compilação de informações de bibliografia, por não serem considerados produção de novos conhecimentos, a pesquisa que tiver acesso aos conhecimentos tradicionais associados de origem identificável precisa de uma autorização dos provedores destes conhecimentos. Esta autorização é denominada consentimento prévio informado e deve cumprir uma série de exigências prescritas na legislação para que seja considerada válida. O descumprimento desta exigência é considerado infração sujeita 
às penalidades previstas na legislação. Além disso, pode interferir na aquisição de direitos de propriedade intelectual.

Assim, é recomendável que os pesquisadores façam buscas a fim de identificar a existência de conhecimento tradicional associado ao patrimônio genético em estudo. Caso nada seja encontrado, é sugerido que possuam registros acerca das metodologias utilizadas e resultados encontrados em sua busca para autodefesa.

Os conhecimentos tradicionais, contudo, não são normalmente encontrados nas fontes acadêmicas e, muitas vezes, sequer são fixados. São transmitidos oralmente no interior dos povos indígenas e comunidades tradicionais. Mas, muitas vezes, estes conhecimentos transbordam e se difundem muito além de seu centro de origem. Alguns destes conhecimentos se difundem com tanta intensidade que, à primeira vista, podem parecer parte do domínio público, tamanha a intensidade de seu transbordamento.

A situação hipotética proposta neste artigo é o encontro fortuito de um conhecimento tradicional associado a recurso genético de origem identificável, em fonte secundária, no contexto de uma pesquisa científica já em andamento. Ainda que seja clara na legislação a exigência do consentimento, sua eventual negativa irá impactar a pesquisa científica, eventuais direitos de propriedade de quem custeia, além daqueles relacionados à investigação científica, e o interesse público nos potenciais resultados.

Seria justo e razoável que pesquisadores e investidores que de boa-fé não conseguiram identificar conhecimentos tradicionais relacionados ao objeto de sua pesquisa, fossem privados de seus direitos e a sociedade privada dos potenciais benefícios desta pesquisa, sem uma justificativa satisfatória, pela simples existência de conhecimentos tradicionais associados encontrados ou divulgados em fonte secundária quando a pesquisa já se encontrava em andamento?

Como garantir aos povos indígenas e comunidades tradicionais o direito de gerir seus próprios saberes e que tenham direito à repartição justa e equitativa decorrente da utilização dos conhecimentos tradicionais associados ao patrimônio genético sem que isso acarrete prejuízos injustificados a direitos fundamentais de terceiros e à própria coletividade?

\section{METODOLOGIA}

A metodologia empregada foi o método dedutivo com suporte em pesquisa documental a partir de legislações nacionais e atos internacionais (acordos, tratados e convenções). Conforme afirma Gil (2002, p. 45):

A pesquisa documental assemelha-se muito à pesquisa bibliográfica. A diferença essencial entre ambas está na natureza das fontes. Enquanto a pesquisa bibliográfica se utiliza fundamentalmente das contribuições dos diversos autores sobre determinado assunto, a pesquisa documental vale-se de materiais que não recebem ainda um tratamento analítico, ou que ainda podem ser reelaborados de acordo com os objetos da pesquisa.

\section{RESULTADOS E DISCUSSÃO}

A Convenção da Diversidade Biológica (CDB) foi o acordo aprovado durante a Rio-92, por 156 países e uma organização de integração econômica regional (CDB, 2020). ${ }^{2}$ Foi ratificada pelo Congresso Nacional Brasileiro e entrou em vigor no final de dezembro de 1993. A CDB reconheceu a importância da contribuição das comunidades locais e populações indígenas com

${ }^{2}$ Atualmente, a CDB conta com 168 países. (CDB, 2020)

Revista de Direito Brasileira | Florianópolis, SC | v. 28 | n. 11 | p.117-130 | Jan./Abr. 2021 
estilos de vida tradicionais na conservação da diversidade biológica e na utilização sustentável de seus componentes.

De acordo com a Fundação Nacional do Índio, entre as áreas significativas de alto valor natural remanescentes no planeta, a maior parte é habitada por povos indígenas (FUNAI, 2015). A contribuição desses povos, através de seus conhecimentos e usos tradicionais, garante a preservação das florestas das quais dependem em uma relação equilibrada entre as sociedades e seus ambientes naturais.

As terras indígenas não fazem parte do Sistema Nacional de Unidades de Conservação, mas possuem papel fundamental na conservação da biodiversidade, pois ocupam $13 \%$ do território brasileiro contra apenas $8,86 \%$ que está protegido em unidades de conservação federais (NASCIMENTO e CAMPOS, 2011).

O sistema agrícola tradicional do Rio Negro é um exemplo emblemático do papel dos povos indígenas e comunidades tradicionais na conservação da biodiversidade. Com suas mais de 100 variedades de mandioca brava (Manihot esculenta), foi registrado no Instituto do Patrimônio Histórico e Artístico Nacional (IPHAN) em 2010 no Livro de Registro dos Saberes como patrimônio imaterial do Brasil. Esse sistema reúne mais de vinte e dois povos indígenas, representantes das famílias linguísticas Tukano Oriental, Aruak e Maku, localizados ao longo do rio Negro em um território que abrange os municípios de Barcelos, Santa Isabel do Rio Negro e São Gabriel da Cachoeira, no Estado do Amazonas, até a fronteira do Brasil com a Colômbia e a Venezuela. Esses povos possuem relevantes conhecimentos sobre o manejo florestal e os locais apropriados para cultivar, coletar, pescar e caçar, formando um conjunto de saberes e modos de fazer enraizados no cotidiano (IPHAN, 2020).

Desde que o Brasil aderiu ao tratado da Organização das Nações Unidas para a Alimentação e a Agricultura sobre recursos fitogenéticos - FAO, a conservação in situ de variedades de plantas, por excelência, pode e deve ser feita pelas populações tradicionais. Sua importância é destacada por Carneiro da Cunha que afirma que os povos tradicionais e indígenas são muito informados sobre o clima e a diversidade biológica locais (FAPESP, 2013). Esse fator se destaca num contexto de erosão da diversidade genética das plantas cultivadas no mundo que constitui grave risco para a segurança alimentar, devido a possibilidade de ataque de pragas agrícolas, como a que assolou a Irlanda e outros países da Europa no século XVI. ${ }^{3}$

Nesse sentido, a CDB, em seu art. $8^{\circ}$, j, incumbiu aos países signatários os deveres de respeitar, preservar e manter os conhecimentos, inovações e práticas das comunidades locais e populações indígenas com estilo de vida tradicionais relevantes à conservação e à utilização sustentável da diversidade biológica, assim como incentivar sua mais ampla aplicação com a aprovação e a participação dos detentores desses conhecimentos, inovações e práticas. Além disso, a CDB também previu o dever de encorajar a repartição equitativa dos benefícios oriundos da utilização desses conhecimentos, inovações e práticas.

Em 2008, o Comitê Intergovernamental sobre propriedade intelectual e recursos genéticos, conhecimentos tradicionais e folclore da World Intellectual Property Organization (WIPO), reunido em Genebra, em sua décima terceira sessão, definiu os conhecimentos tradicionais em sentido estrito, objeto de proteção jurídica, como aqueles (WIPO, 2008):

- Que tenham sido criados e preservados em um contexto tradicional, transmitindose de uma geração à outra;

- Que estejam particularmente vinculados a um povo ou comunidade indígena ou tradicional, que os preserva e transmite de uma geração à outra; e

\footnotetext{
${ }^{3}$ Ainda que se possa afirmar que os bancos de germoplasma (unidades de conservação de material genético de plantas de uso imediato ou com potencial de uso futuro) tenham amenizado esse risco, não se pode perder de vista que as plantas coevoluem com os ambientes, que também mudam com o passar do tempo, fazendo-se necessário complementá-los com ações de conservação in situ.
}

Revista de Direito Brasileira | Florianópolis, SC | v. 28 | n. 11 | p.117-130 | Jan./Abr. 2021 
- Que sejam parte integrante da identidade cultural de um povo ou comunidade indígena ou tradicional, que é reconhecido como seu titular porque sobre eles exerce sua custódia, conservação, titularidade coletiva ou responsabilidade cultural, ainda que não seja oficialmente.

Assim, segundo WIPO (2008), para merecer a proteção, os conhecimentos tradicionais devem possuir um caráter intergeracional, estar vinculados objetivamente à comunidade de origem e manter uma associação subjetiva dentro da dita comunidade, de maneira que formem parte da própria identidade desta comunidade.

A legislação brasileira define o conhecimento tradicional associado (CTA) como "informação ou prática de população indígena, comunidade tradicional ou agricultor tradicional sobre as propriedades ou usos diretos ou indiretos associada ao patrimônio genético" (BRASIL, 2015). Este conhecimento pode ser reconhecido de diversas formas, incluindo publicações científicas, registros em cadastros ou bancos de dados e inventários culturais. ${ }^{4}$ Seu acesso pode decorrer de fontes primárias, diretamente junto aos provedores de conhecimentos tradicionais, mas o acesso também pode se dar por fontes secundárias tais como feiras, publicações, inventários, filmes, artigos científicos, cadastros e outras formas de sistematização e registro (BRASIL, 2015; BRASIL, 2016).

Kamau (2009, p. 170) destaca que, devido à disseminação irrestrita e livre do CTA sobre um longo período, uma porção significativa de conhecimentos tradicionais não está mais sob o controle das populações indígenas e comunidades locais. Segundo ele, existem três níveis identificáveis nos quais o CTA é mantido. É considerado intacto o CTA que permanece dentro das comunidades locais e indígenas. Em um segundo nível, esse conhecimento já é considerado disseminado em âmbito nacional. E a disseminação em nível mundial constitui o terceiro nível de disseminação do CTA.

A legislação brasileira, todavia, não considera estas camadas de disseminação do conhecimento. ${ }^{5}$ Essa lacuna acarreta insegurança jurídica na medida em que trata do CTA intacto, difundido apenas entre os provedores de CTA, de maneira indistinta do CTA difundido regional, nacional ou globalmente.

Há ainda mais um fator de complexidade. Suponhamos que um antigo saber popular tenha sido incorporado por uma comunidade tradicional. Pode acontecer que não se tenha mais como identificar a origem precisa desse conhecimento, de modo que não se possa dizer se foi um saber tradicional que se popularizou ou um saber popular que foi assimilado pela comunidade tradicional. Este conhecimento que pertencia ao domínio público passaria a ser apropriado por um povo indígena ou comunidade tradicional que o assimilou, distorcendo a justiça e a lógica do sistema.

O conhecimento amplamente difundido e disponível não necessariamente é incorporado ao domínio público, que é composto por três partes. O estatuto jurídico dos materiais estabelece que o domínio público corresponde aos recursos livres de direitos de propriedade intelectual (PI). Estariam aí todos os produtos intelectuais que nunca estiveram ou já não estão sob a proteção da PI, incluindo material não elegível para proteção (p. ex. por falta de novidade ou atividade inventiva para patente), material que foi liberado em decorrência de anulação ou expiração de um direito de PI e material que poderia ser protegido mas não foi porque não foi requerida a proteção (WIPO, 2010).

\footnotetext{
${ }^{4}$ Além das características mencionadas acima, a lei ainda afirma que qualquer conhecimento tradicional associado ao patrimônio genético será considerado de natureza coletiva, ainda que apenas um indivíduo de população indígena ou de comunidade tradicional o detenha (Brasil, 2015).

${ }^{5}$ A Lei $n^{0} 13123 / 15$ se refere apenas à isenção das obrigações da lei no intercâmbio e na difusão de PG e de CTA praticados entre si por populações indígenas, comunidade tradicional ou agricultor tradicional para seu próprio benefício e baseados em seus usos, costumes e tradições (Brasil, 2015).
} 
A segunda parte do domínio público é a liberdade de utilizar, segundo a qual, o domínio público é formado pelo material livre ou disponível a qualquer um para usar para qualquer fim, sem necessidade de autorização e de maneira gratuita (WIPO, 2010).

A terceira parte do domínio público é a disponibilidade e acessibilidade dos materiais. Disponibilidade pública não significa disponibilidade gratuita. E ainda que haja disponibilidade pública e gratuita, isso não significa que o acesso seja desprovido de regras. Ao contrário, a disponibilidade pública não se contrapõe à ideia da estipulação de regras mutuamente acordadas, tais como o pagamento ou a repartição de benefícios pelo acesso ao conhecimento. Mesmo a disponibilidade por meio de uma fonte aberta e sem qualquer ônus não significa que faça parte do domínio público. Por isso, importa distinguir os conhecimentos tradicionais que pertencem ao domínio público dos conhecimentos tradicionais publicamente disponíveis (WIPO, 2010).

Parte dos conhecimentos tradicionais são considerados como parte do domínio público, livremente disponíveis, por força do seu acesso, de sua extração do contexto cultural e de sua ampla disseminação. Mas, em relação aos conhecimentos tradicionais associados ao patrimônio genético, é mais difícil afirmar que não pertençam a ninguém, justamente pela ligação indissociável entre os conhecimentos e seus provedores com o centro de origem do patrimônio genético associado. Mesmo que as espécies não sejam endêmicas, sempre há um centro de origem cujo entorno favorece à identificação dos provedores de conhecimentos tradicionais. Assim, mesmo que disponível publicamente, se for possível identificar pelo menos um provedor destes saberes, será necessário obter seu consentimento e repartir os benefícios, quando for o caso (WIPO, 2010).

A legislação conceitua consentimento prévio informado (CPI) como "consentimento formal, previamente concedido por população indígena ou comunidade tradicional segundo os seus usos, costumes e tradições ou protocolos comunitários". ${ }^{6} \mathrm{O}$ CPI é uma condição para o acesso ao CTA de origem identificável. ${ }^{7}$

Sua previsão tem fundamento na Convenção $\mathrm{n}^{\circ} 169$ da OIT sobre Povos Indígenas e Tribais, promulgada pelo Decreto $n^{\circ}$ 5.051, de 19/04/2004. De acordo com o art. $6^{\circ}$, 1, a), desta Convenção, os governos deverão consultar os povos interessados, mediante procedimentos apropriados e, particularmente, através de suas instituições representativas, cada vez que sejam previstas medidas legislativas ou administrativas suscetíveis de afetá-los diretamente. ${ }^{8}$ Essas consultas deverão ser efetuadas com boa fé e de maneira apropriada às circunstâncias, com o objetivo de se chegar a um acordo e conseguir o consentimento acerca das medidas propostas (BRASIL, 2004). Segundo diversas lideranças de povos indígenas e de comunidades tradicionais, isto não ocorreu em relação à Lei $\mathrm{n}^{\circ} 13.123 / 15$, havendo claras e variadas violações a esta Convenção no processo de elaboração desta legislação (MOREIRA, 2017).

$\mathrm{O}$ art. $7^{\circ}$ da Convenção $\mathrm{n}^{\circ} 169$ da OIT assegura aos povos indígenas e tribais o direito de escolher suas próprias prioridades no que diz respeito ao processo de desenvolvimento, na medida em que ele afete as suas vidas, crenças, instituições e bem-estar espiritual, bem como as terras que ocupam ou utilizam de alguma forma. Este dispositivo também assegura o direito de controlar, na medida do possível, o seu próprio desenvolvimento econômico, social e cultural.

$\mathrm{O}$ art. $8^{\circ}$ da Convenção destaca o respeito aos costumes e ao direito consuetudinário. Afirma o direito de conservar seus costumes e instituições próprias, desde que guardem compatibilidade com os direitos fundamentais definidos pelo sistema jurídico nacional e com os

\footnotetext{
${ }^{6}$ Considerando que o inciso $\mathrm{V}$, do mesmo artigo, da mesma lei, também considera o agricultor tradicional como possível provedor de CTA, ele deveria também constar no conceito de consentimento prévio informado. Mas, isso não ocorreu.

${ }^{7}$ A lei $n^{\circ} 13.123 / 15$ não conceitua o conhecimento tradicional de origem identificável, mas conceitua o conhecimento tradicional associado de origem não identificável como o conhecimento tradicional associado em que "não há a possibilidade de vincular a sua origem a, pelo menos, uma população indígena, comunidade tradicional ou agricultor tradicional".

${ }^{8}$ Por se tratar de uma convenção internacional que trata de direitos humanos, possui um status legal superior ao das leis ordinárias, como a lei $\mathrm{n}^{\text {os }} 13.123 / 15$, por exemplo, mas ainda abaixo da Constituição Federal.
} 
direitos humanos internacionalmente reconhecidos. Recomenda ainda o dispositivo que sejam estabelecidos mecanismos de resolução de conflitos decorrentes da aplicação deste princípio.

$\mathrm{Na}$ situação hipotética sugerida, pode ocorrer a incompatibilidade desta Convenção, internalizada com status legal superior à da legislação federal de patrimônio genético e conhecimentos tradicionais, em relação aos direitos fundamentais protegidos na Constituição Federal. A colisão do direito dos povos indígenas e comunidades tradicionais de negar acesso aos conhecimentos tradicionais, na situação hipotética, pode se dar com os direitos fundamentais relativos à saúde pública, à propriedade e ao desenvolvimento social, tecnológico e econômico.

De acordo com dados da World Health Organization (WHO) de 2013, cerca de 25\% das drogas prescritas mundialmente vêm das plantas e, entre as 252 drogas consideradas como básicas e essenciais pela entidade, $11 \%$ têm origem exclusiva em plantas e um número significativo de drogas sintéticas são obtidas a partir de precursores naturais (WHO, 2013).

Uma única espécie vegetal como a Uncaria tomentosa (nome popular: unha de gato) já gerou 160 patentes no Brasil na classificação A61K (medicamentos e produtos voltados para a saúde) e quatro produtos com registro na Anvisa, com indicações coincidentes com os conhecimentos tradicionais já testados (OLIVEIRA e NOGUEIRA, 2017). A negativa de acesso aos conhecimentos tradicionais na situação hipotética sugerida precisa de fundamentação suficiente para fazer face aos evidentes prejuízos à saúde pública que a negativa pode causar. A saúde é um direito fundamental protegido constitucionalmente e, portanto, do mesmo status do direito dos povos indígenas e comunidades tradicionais.

Na situação hipotética sugerida, a pesquisa já se encontrava em andamento, ou seja, já havia um aporte de investimento, público ou privado, que será perdido caso a pesquisa seja interrompida por falta de consentimento dos provedores de CTA. Isso afeta o direito fundamental de propriedade de quem arcou com o investimento, seja o erário público, seja uma iniciativa privada.

Nesse ponto é importante retomar a categorização de três níveis estabelecida por Kamau (2009, p. 170) para CTA de origem identificável e a situação hipotética aqui em análise, pois no caso de CTA de origem identificável - restrito, ou seja, que não tenha sido divulgado fora da comunidade, condicionar a negação do acesso a uma motivação específica seria, na prática, forçar a comunidade a revelar algo que ainda não está revelado. No entanto, não é disso que se trata em absoluto no caso hipotético, pois na situação em análise, o conhecimento já havia sido divulgado numa fonte secundária.

Outro ponto a se considerar a partir da categorização de Kamau $(2009$, p.170) é que com a disseminação da internet e de tradutores automáticos, qualquer documento existente em formato eletrônico num determinado idioma e acessível na internet estaria sujeito ao alcance de qualquer um em nível mundial, o que reduziria a questão, na prática, a existência de duas categorias analíticas com as quais trabalharemos neste artigo, quais sejam: Conhecimento Tradicional Associado de Origem Identificável Restrito (CTAOIR) e Conhecimento Tradicional Associado de Origem Identificável Disseminado (CTAOID).

Assim, conferir um estatuto de reconhecimento ao CTAOID, que o reconheça como tal no andamento de pesquisas científicas, para que depois se estabeleça a repartição justa e equitativa quando, a partir deste, se chegue a um produto no mercado, é fundamental.

A Constituição brasileira estabelece que é competência comum da União, dos Estados, do Distrito Federal e dos Municípios proporcionar os meios de acesso à educação, à ciência, à tecnologia, à pesquisa e à inovação, sendo a liberdade de aprender, ensinar, pesquisar e divulgar o pensamento, a arte e o saber um dos mais significativos princípios constitucionais relativos à educação (BRASIL, 1988).

Destacam-se ainda a autonomia didático-científica das universidades e das instituições de pesquisa científica e tecnológica e a garantia de acesso aos níveis mais elevados do ensino, da pesquisa e da criação artística, segundo a capacidade de cada um, como dever do Estado, assim 
como a promoção e o incentivo do desenvolvimento científico, da pesquisa, da capacitação científica e tecnológica e da inovação (BRASIL, 1988).

A Constituição vai além, afirmando que a pesquisa científica básica e tecnológica receberá tratamento prioritário do Estado, tendo em vista o bem público e o progresso da ciência, tecnologia e inovação. No mesmo sentido, o §único do art. 219 da Constituição coloca a difusão como um dos instrumentos do Estado para incentivar o desenvolvimento cultural e socioeconômico, o bem-estar da população e a autonomia tecnológica do país (BRASIL, 1988).

Barbosa (2010, p. 98) identificou estas tensões constitucionais, destacando a proteção dos interesses do investidor e do criador e o princípio do uso social das propriedades, a cláusula finalística da propriedade industrial, os parâmetros constitucionais de proteção à tecnologia, à autonomia tecnológica e à cultura, e as liberdades constitucionais de criação artística e de expressão.

Uma questão subjacente a toda a discussão até aqui apresentada diz respeito à aplicação da legislação em relação aos atos realizados no exterior. Ainda que haja previsão de penalidades por estes atos como, por exemplo, divulgar resultados, finais ou parciais, em meios científicos ou de comunicação sem cadastro prévio ou requerer direito de propriedade intelectual resultante de acesso ao patrimônio genético ou conhecimento tradicional associado, no Brasil ou no exterior, sem realização de cadastro prévio (BRASIL, 2016), a aplicação da lei extra territorialmente apresenta dificuldades.

A carência de infraestrutura institucional em âmbito internacional para este tipo de situação, tende a deixar impune quem viola a legislação no exterior, enquanto para os nacionais resta o rigor da lei. Assim cria-se com a lei uma curiosa assimetria que prejudica a pesquisa nacional e beneficia a pesquisa estrangeira sobre o patrimônio genético e os conhecimentos tradicionais brasileiros. Espera-se que a implantação do mecanismo de Certificados de Conformidade reconhecidos internacionalmente, previsto no Protocolo de Nagoia, possa começar a tratar esta assimetria (CDB, 2014).

Sendo assim, embora represente um claro avanço em relação a MP $n^{\circ} 2.186-16$, a Lei $n^{\circ}$ $13.123 / 2015$ não superou totalmente as críticas em relação ao instrumento legal anterior no que tange ao funcionamento como eventual barreira para as pesquisas científicas. No caso hipotético específico, o sistema demonstra uma assertividade muito maior com o controle da informação que está sendo pesquisada em fontes secundárias em âmbito nacional do que com a mesma situação quando ocorrida no exterior.

Além disso, impõe uma precoce barreira na pesquisa científica que, logicamente, deveria ter seu ponto de controle estabelecido em estágio mais avançado e mais próxima ao mercado se o foco principal do CPI sobre CTAOID na legislação centrasse na repartição justa e equitativa dos benefícios. Afinal, ficando obstada a pesquisa por ausência de consentimento prévio informado, ainda que potencialmente irrelevante e obtido tardiamente em fontes secundárias, não há que se falar em novos conhecimentos e inovação, o que prejudica não apenas o avanço da ciência, mas a coletividade e os próprios povos indígenas e comunidades tradicionais que poderiam se beneficiar do progresso científico em diversas áreas como a saúde e a ecologia, por exemplo.

\section{CONCLUSÃO}

Trata-se de hipótese de colisão múltipla de direitos fundamentais. A solução para essas questões se relaciona estreitamente com o princípio da proporcionalidade. De acordo com este princípio, algumas regras precisam ser observadas.

A solução de uma colisão entre direitos fundamentais exige que haja o sacrifício parcial de um direito em detrimento de outro. Este sacrifício precisa ser necessário, adequado e proporcional. Ou seja, deve ser útil para a solução do problema, não deve haver outro meio menos danoso para se atingir o fim desejado e o benefício pretendido deve ser superior ao sacrifício. Além 
disso, os direitos fundamentais contrapostos devem ser reduzidos à sua essência (ANDRADE, 1987), de forma a garantir que não haja a necessidade de se anular integralmente um deles (princípio da proteção do núcleo essencial). A solução de uma colisão desta natureza passa necessariamente pela aplicação dos princípios da concordância prática e da unidade constitucional, evitando a colisão irredutível de direitos fundamentais constitucionalmente protegidos (MENDES e BRANCO, 2018).

Ocorre que, em tese, existem argumentos fortes de todos os lados e a decisão não pode ficar a cargo exclusivo da subjetividade de quem julga a colisão. Em razão disso, a doutrina atingiu considerável consenso no sentido de que a colisão de direitos fundamentais só pode ser efetivamente solucionada sobre o caso em concreto. $\mathrm{O}$ raciocínio que aplica a proporcionalidade para a solução desta colisão precisa se certificar da confiabilidade das premissas empíricas em que se baseia, aferindo o verdadeiro significado da solução proposta em relação aos direitos fundamentais em colisão (ALEXY, 2006).

Independente das peculiaridades de cada pesquisa e de cada conhecimento tradicional associado, é possível aprimorar o sistema legal a fim de reduzir os custos de transação deste tipo de operação por meio da redução da insegurança jurídica.

A adequação deve estabelecer balizas sobre a negativa de acesso ao CTA no sentido de promover proporcionalidade no exercício dos legítimos direitos dos povos indígenas e comunidades tradicionais. Nossa sugestão é que sejam tipificadas e distintas na legislação duas situações relacionadas ao acesso a CTA de origem identificável.

A primeira situação diz respeito ao CTA de origem identificável que se encontra restrito aos limites dos povos indígenas e comunidades tradicionais, em que a cooperação dos provedores destes saberes se faz necessária.

A segunda situação seria aquela em que o CTA de origem identificável já esteja disseminado. Neste segundo caso, é recomendável que seja estabelecida a necessidade de motivação e fundamentação para a negação do acesso, tal como a Constituição prevê para as decisões administrativas e judiciais (art. 93, IX e X) (BRASIL, 1988) de maneira pública, sob pena de nulidade, podendo a lei limitar a presença, em determinados atos, às próprias partes, às entidades representativas e a seus advogados, ou somente a estes, em casos nos quais a preservação do direito à intimidade do interessado no sigilo não prejudique o interesse público à informação.

A exigência de motivação possibilita um melhor exercício do direito de ação pelos prejudicados na sugestão hipotética em questão. Os órgãos e entidades federais de proteção dos direitos, de assistência ou de fomento das atividades das populações indígenas, comunidades tradicionais e agricultores tradicionais deverão, a pedido destes, assessorar as atividades de obtenção de consentimento prévio informado e a negociação dos acordos de repartição de benefícios, podendo contar com o apoio do Conselho de Gestão do Patrimônio Genético do Ministério do Meio Ambiente.

A motivação e a fundamentação devem ser comprovadas pelos mesmos meios admitidos para comprovação do consentimento prévio informado, a critério da população indígena, da comunidade tradicional ou do agricultor tradicional, pela assinatura de termo próprio de motivação e fundamentação, por registro audiovisual da negativa do consentimento, por parecer do órgão oficial competente ou na forma prevista em protocolo comunitário.

A distinção entre as situações de CTA associado ao patrimônio genético de origem identificável restrito e disseminado e o atrelamento da segunda situação à necessidade de motivação para a negativa de acesso poderá contribuir substancialmente para evitar o impedimento imotivado de pesquisas científicas e para que continue caracterizada a linha que liga um determinado avanço científico, tecnológico ou inventivo a um determinado conhecimento tradicional, facilitando assim a comprovação de acesso e a percepção de benefícios pela exploração econômica por terceiros, direta ou indiretamente, de conhecimento tradicional associado. 
Como, diferente da terra, a informação é um bem não rival, ou seja, uma pessoa não precisa utilizá-la menos pelo fato de outro também a estar utilizando, a questão do reconhecimento da utilização do conhecimento tradicional associado numa pesquisa científica a partir de uma fonte secundária passa muito mais pela questão da repartição justa e equitativa do benefício auferido pela exploração econômica por terceiros do que pela cessação do direito de fruição do referido conhecimento pela própria comunidade, tendo em vista tratar-se de um direito reconhecido pela Constituição brasileira. Além disso, a própria Lei n ${ }^{\circ}$ 13.123/2015 garante às populações indígenas, às comunidades tradicionais e aos agricultores tradicionais que criam, desenvolvem, detêm ou conservam conhecimento tradicional associado os direitos de usar ou vender livremente produtos que contenham patrimônio genético ou conhecimento tradicional associado.

Assim, os conhecimentos tradicionais que já estão sistematizados e descritos em fontes secundárias tem importância dupla: por um lado impedir a apropriação indevida por terceiros quando da tentativa de apropriação de conhecimentos que não são mais novos e por outro garantir a repartição justa e equitativa dos benefícios quando da geração de um produto ou processo a partir de pesquisa que utilizou esses conhecimentos.

Por essas questões, a distinção de procedimentos em relação ao que é CTAOIR e o que é CTAOID seria tão importante na legislação. Na primeira situação, não há que se falar em motivação para negativa de acesso para um conhecimento que ainda não foi disseminado, uma vez que a comunidade tradicional pode simplesmente não ter interesse em revelá-lo. $\mathrm{Na}$ segunda situação, essa discussão se torna bastante pertinente pois há que se ponderar quanto de vínculo objetivo e associação subjetiva há no conhecimento disseminado em diferentes fontes, inclusive nas relativas à conhecimentos tradicionais. Também implica admitir a complexidade da circularidade de conhecimentos, valores e práticas que tem constituído as trocas de conhecimento ao longo dos 520 anos de colonização do Brasil, ao invés de legitimar-se somente para fins de reconhecimento daqueles direitos exclusivos que fluem unidirecionalmente de comunidades tradicionais para a nossa sociedade científica e técnica.

No entanto, como para o reconhecimento de direitos exige-se uma "pureza" destes conhecimentos tradicionais, ou em outras palavras segundo menção do próprio Comitê Intergovernamental da WIPO, que estejam particularmente vinculados a um povo ou comunidade indígena ou tradicional, que os preserva e transmite de uma geração à outra, basear-se na premissa da circularidade e mesclagem destes conhecimentos só serviria, no constructo legal vigente, para negar-lhes o próprio e legítimo direito. Por isso, países como a Índia têm se esforçado por sistematizar esse conhecimento em bases de dados como o Traditional Knowledge Digital Library que é uma iniciativa pioneira para proteger o conhecimento medicinal tradicional indiano de apropriação patentária indevida ao redor do mundo por meio da garantia do acesso aos examinadores de patentes ao estado da técnica na área, sem restringir o uso dos conhecimentos tradicionais.

O aprimoramento das regras a respeito da motivação para a negativa de acesso aos CTAOID para a pesquisa científica pode impulsionar o aproveitamento social e econômico destes saberes e contribuir para o incremento do intercâmbio entre a comunidade científica e os povos indígenas e comunidades tradicionais, sem deslegitimá-los. O encontro fortuito de CTA de origem identificável por pesquisa científica já em andamento não deve ser solucionado por uma regra que atribui um grau absoluto a um direito fundamental, desconsiderando a unidade da Constituição e a necessidade de concordância prática entre os direitos fundamentais.

$\mathrm{O}$ direito de pesquisa científica deve respeitar o direito dos povos indígenas e comunidades tradicionais de controlar o acesso aos seus conhecimentos, mas, por outro lado, o direito de controlar o acesso às informações já disseminadas não deve ser arbitrário, estanque e dispensado de fundamentação e motivação, sob pena de se tornar mero instrumento de barganha. Para atender às exigências do nosso sistema constitucional, a justificativa para a negativa de acesso aos CTAOID deve ter peso suficiente para se sobrepor aos potenciais benefícios da pesquisa 
científica e deve levar em conta também o interesse social de maneira a não privar a sociedade, incluindo-se aí as próprias comunidades tradicionais, de estudos ou pesquisas científicas ou tecnológicas que estejam utilizando conhecimentos disponíveis no estado da técnica.

\section{REFERÊNCIAS}

ALEXY, Robert. Teoria dos Direitos Fundamentais, Suhrkamp Verlag, 1986. Tradução de Virgílio Afonso da Silva da $5^{\mathrm{a}}$ edição alemã Theorie der Grundrechte publicada pela Suhrkamp Verlag (2006). Malheiros Editores. ISBN 978-85-7420-872-5.

ANDRADE, José Carlos Vieira de. 1987. Os direitos fundamentais na Constituição portuguesa de 1976. Coimbra: Almedina.

BARBOSA, Denis Borges. 2010. Uma introdução à Propriedade Intelectual. Ed. Lumen Juris. Disponível em http://www.nbb.com.br/pub/denis/introducao_pi.pdf Acesso em 26/11/18.

BRASIL. Constituição da República Federativa do Brasil. 1988.

BRASIL. Decreto Legislativo No 2, de 1994. Aprova o texto do Convenção sobre Diversidade Biológica, assinada durante a Conferência das Nações Unidas sobre Meio Ambiente e Desenvolvimento, realizada na Cidade do Rio de Janeiro, no período de 5 a 14 de junho de 1992. Disponível em https://www2.camara.leg.br/legin/fed/decleg/1994/decretolegislativo-2-3fevereiro-1994-358280-norma-pl.html Acesso em 08/05/2020.

BRASIL. Decreto No 2.519, de 16 de março de 1998. Promulga a Convenção sobre Diversidade Biológica, assinada no Rio de Janeiro, em 05 de junho de 1992. Disponível em http://www.planalto.gov.br/ccivil_03/decreto/D2519.htm Acesso em 08/05/2020.

BRASIL. Decreto nº 5.051, de 19 de abril de 2004. Promulga a Convenção no 169 da Organização Internacional do Trabalho - OIT sobre Povos Indígenas e Tribais. Disponível em < http://www.planalto.gov.br/ccivil_03/_ato2004-2006/2004/decreto/d5051.htm> Acesso em 30/05/2018.

BRASIL. Lei $n^{\circ} 13.123$, de 20 de maio de 2015. Regulamenta o inciso II do $\S 1^{\circ}$ e o $\S 4^{\circ}$ do art. 225 da Constituição Federal, o Artigo 1, a alínea j do Artigo 8, a alínea c do Artigo 10, o Artigo 15 e os $\S \S 3^{\circ}$ e $4^{\circ}$ do Artigo 16 da Convenção sobre Diversidade Biológica, promulgada pelo Decreto no 2.519, de 16 de março de 1998; dispõe sobre o acesso ao patrimônio genético, sobre a proteção e o acesso ao conhecimento tradicional associado e sobre a repartição de benefícios para conservação e uso sustentável da biodiversidade; revoga a Medida Provisória no 2.186-16, de 23 de agosto de 2001; e dá outras providências. Disponível em:

<http://www.planalto.gov.br/ccivil_03/_Ato2015-2018/2015/Lei/L13123.htm> Acesso em: 17 jun. 2018.

BRASIL. Decreto no 8.772, de 11 de maio de 2016. Regulamenta a Lei $n^{\circ} 13.123$, de 20 de maio de 2015, que dispõe sobre o acesso ao patrimônio genético, sobre a proteção e o acesso ao conhecimento tradicional associado e sobre a repartição de benefícios para conservação e uso sustentável da biodiversidade. Disponível em < http://www.planalto.gov.br/ccivil_03/_ato20152018/2016/decreto/D8772.htm> Acesso em 30/05/18. 
BRASIL, Katia. 2000. "Bioprospecção. Contrato sofre revisão. Bioamazônia altera acordo com Novartis.” Folha de São Paulo. 07 ago 2000.

https://www1.folha.uol.com.br/fsp/ciencia/fe0708200003.htm

CDB. 2020. Convenção da Diversidade Biológica. https://www.cbd.int/information/parties.shtml

CDB. 2014. Protocolo de Nagoia sobre acesso a recursos genéticos e repartição justa e equitativa dos benefícios derivados de sua utilização à Convenção sobre Diversidade Biológica. / Secretariado da Convenção sobre Diversidade Biológica e Ministério do Meio Ambiente. Brasília: DPG/SBF/MMA, 2014. 42 p. ISBN 978-85-7738-190-6

CNI. Confederação Nacional da Industria. 2017. Acesso e repartição de benefícios no cenário mundial: a lei brasileira em comparação com as normas internacionais/Confederação Nacional da Indústria, GSS Sustentabilidade e Bioinovação, Natura Inovação e Tecnologia de Produtos Brasília.

DEAN, Warren. 1987. Brazil and the Struggle for Rubber. Cambridge: Cambridge University Press. Traduzido para o português como "O Brasil e a luta pela borracha". São Paulo: Ed. Nobel, 1991.

FAPESP. Povos tradicionais têm papel crucial na conservação da biodiversidade. Publicado em 22 de julho de 2013.

http://agencia.fapesp.br/povos_tradicionais_tem_papel_crucial_na_conservacao_da_biodiversida de_/17584/

FUNAI. Fundação Nacional do Índio. 2015. Diretoria de Proteção Territorial; Coordenação Geral de Monitoramento Territorial; giz (orgs.). Serviços ambientais: o papel das terras indígenas: Programa de Capacitação em Proteção Territorial. - Brasília:FUNAI/GIZ, 2015. 179p. Ilust. ISBN: 978-85-7546-046-7

GIL, Antônio Carlos, 1946. Como elaborar projetos de pesquisa/Antônio Carlos Gil. - 4. ed. São Paulo: Atlas, 2002. Bibliografia. ISBN 85-224-3169-8.

IPHAN. Instituto do Patrimônio Histórico e Artístico Nacional. 2020. Sistema Agrícola Tradicional do Rio Negro. http://portal.iphan.gov.br/pagina/detalhes/75 Acesso em 17/07/2020.

JOLY, Carlos Alfredo. 2000. Curupira x Biopirataria - O Acordo de Cooperação Técnica entre a BioAmazônia e a Novartis. Revista Pesquisa Fapesp. Edição 54. jun 2000.

KAMAU, Evanson Chege, 2009. A implementação do artigo 8j da CDB, o problema do conhecimento tradicional disseminado e a experiência do Quênia, in: Kishi / Kleba (Hg.), Dilemas do Acesso à Biodiversidade e Aos Conhecimentos Tradicionais, Direito, Política e Sociedade, Belo Horizonte: Editora Fórum, S. 157 - 190. ISBN-10: 8577002403. ISBN-13: 9788577002405 .

MENDES, Gilmar Ferreira. BRANCO, Paulo Gustavo Gonet. 2018. Curso de Direito Constitucional. 13a ed. Ed. Saraivajur. ISBN 978-85-472-2974-0. 
MOREIRA, Eliane Cristina Pinto (Org.). 2017.A “Nova” Lei N. ' 13.123/2015 no velho marco legal da biodiversidade: Entre Retrocessos e Violações de Direitos Socioambientais./ Eliane Cristina Pinto Moreira (Org.); Noemi Miyasaka Porro (Org.); Liana Amin Lima da Silva (Org.). - São Paulo : Inst. O direito por um Planeta Verde, 2017. ISBN 978-85-63522-37-5.

MOREIRA, Teresa Cristina. 2005. O acesso ao patrimônio genético e aos conhecimentos tradicionais associados e os direitos de comunidades indígenas e locais no Brasil. In Direitos de recursos tradicionais: formas de proteção e repartição de benefícios. Editores: Lin Chau Ming... (et al.) - Botucatu: Unesp, 2005.

NASCIMENTO, Jorge Luiz do. CAMPOS, Ivan Braga. 2011. Atlas da Fauna Brasileira Ameaçada de Extinção em Unidades de Conservação Federais. Brasília. 2011. ISBN: 978-8561842-22-2.

OLIVEIRA, Ana Claudia Dias de. NOGUEIRA, Marcelo. 2017. A relação entre o conhecimento tradicional associado e as patentes relacionadas à Uncaria tomentosa (unha de gato). Anais: $\mathrm{X}$ ENAPID: X Encontro Acadêmico de Propriedade Intelectual, Inovação e Desenvolvimento. Coordenação: Rita Pinheiro Machado, Ricardo Carvalho Rodrigues e Celso Salgueiro Lage. Rio de Janeiro, RJ: INPI. ISBN: 978-85-87543-11-0

PEDRO, Antonio. Fernando Pinheiro. Biodiversidade brasileira e os contratos de bioprospecção (O caso BioAmazônia - Novartis). 2018. Disponível em http://pinheiropedro.com.br/site/artigos/biodiversidade-brasileira-e-os-contratos-debioprospeccao-o-caso-bioamazonia-novartis/ Acesso em 07/04/2020

ROBINSON, Daniel. 2010. Confronting Biopiracy: Challenges Cases and International Debate. Earthscan, Oxford, UK. ISBN 978-1-84407-722-9.

VOGEL, Joseph Henry. 2005. Sovereignty as a Trojan Horse: How the Convention on Biological Diversity Morphs Biopiracy Into Biofraud [online]. In: Hocking, Barbara Ann (Editor). Unfinished Constitutional Business?: Rethinking Indigenous Self-determination. Canberra: Aboriginal Studies Press, 2005: 228-247. ISBN: 0855754664.

WHO. World Health Organization. 2013. WHO traditional medicine strategy: 2014-2023. 1.Medicine, Traditional. 2.Complementary therapies. 3.Health planning. 4.Delivery of health care. 5.Health policy. ISBN 9789241506090.

WIPO. World Intellectual Property Organization. 2010. Note on the meanings of the term "public domain" in the intellectual property system with special reference to the protection of traditional knowledge and traditional cultural expressions/expressions of folklore. Document prepared by the Secretariat. Intergovernmental Committee on Intellectual Property and Genetic Resources, Traditional Knowledge and Folklore. Seventeenth Session. Geneva, December 6 to 10, 2010.

WIPO. World Intellectual Property Organization. 2008. Intergovernmental Committee on Intellectual Property and Genetic Resources, Traditional Knowledge and Folklore: Thirteenth Session. 2008. The Protection of Traditional Knowledge: Draft Gap Analysis: Revision. Geneva. Switzerland. 